\title{
Viajeros españoles en los países rumanos en el siglo XVI: Diego Galán y su relato sobre Valaquia ${ }^{1}$
}

\author{
Spanish Travelers in the Romanian \\ Countries in the $16^{\text {th }}$ Century. Diego Galán \\ and his Description of Wallachia
}

\author{
Oana Andreia Sâmbrian \\ Academia Rumana \\ Instituto de Ciencias Sociales y Humanidades, Craiova
}

\section{RESUMEN}

El artículo se propone traer a colación un tema casi sin estrenar en el campo de la literatura de viajes: el relato de Diego Galán sobre Valaquia, tema sobre el que, hasta la fecha, no existe más que un artículo publicado hace 50 años por Alexandru Ciorãnescu. Nuestro estudio propone un nuevo análisis del texto, desde una doble perspectiva, histórico-filológica, gracias a la cual se podrá indagar mejor en la creación incipiente del prototipo de la cultura y del espacio rumano en la mentalidad española.

Palabras Clave: Diego Galán; Valaquia; siglo XVI; guerras antiotomanas; literatura de viaje.

\section{ABSTRACT}

The article focuses on a very little explored subject to date, within the field of travel literature: the description of Wallachia, made by Diego Galán. Only one article has been published until today on this topic. His author was Alejandro Ciorãnescu and the article was published 50 years ago. Our study intends to provide a different analysis of the text, throughout a double, historical and philological perspective that contributes to understand better the creation and integration of the Romanian space and culture to the Spanish collective imaginary.

Key words: Diego Galán; Wallachia; $16^{\text {th }}$ Century; Anti Ottoman Wars; Travel Literature.

${ }^{1}$ Este trabajo se inserta en el contrato POSDRU/159/1.5/S/133255, proyecto estratégico ID 133255 (2014), cofinanciado por el Fondo Social Europeo, mediante el Programa Operacional Sectorial Desarrollo de los Recursos Humanos 2007-2013.

Copyright: (C) 2016 CSIC. Este es un artículo de acceso abierto distribuido bajo los términos de una licencia de uso y distribución Creative Commons Attribution (CC-by) España 3.0. 
El viaje constituye una de las formas más directas de conocimiento y de información acerca del otro, así como de manipulación de los que desconocen la realidad y toman por verdaderos los hechos contados por los que sí han tenido el privilegio de acercarse a nuevos espacios. Los viajes brindan la ocasión de aproximarse al otro, de conocer y de autoconocerse, tal como vamos a comprobar mediante el relato del militar renacentista Diego Galán, viajero cuyo relato ocupa, o debería de ocupar un lugar muy importante en la historiografía rumana, debido a su extensión y a la información que proporciona sobre el territorio rumano.

Las primeras menciones de viajeros españoles sobre Rumanía se registran a partir de la segunda mitad del siglo XII, cuando Benjamín de Tudela inició una larga jornada con fines religiosos que incluía la Península Balcánica, mencionando en tal ocasión a los valacos de Thessalia (1160) (Sâmbrian, 2012: 27).

Al principio de sus periplos, los españoles no distinguían entre las tres regiones históricas de Rumanía (Valaquia, Moldavia y Transilvania), con lo cual se limitaban a transmitir información únicamente sobre los «valacos». En la Chronica Hispaniae ab origine prima (1243), Rodríguez Jiménez Rada trazaba la primera lista medieval de los pueblos y de las lenguas europeas, incluyendo el rumano en una lista aparte de la Romania junto con el búlgaro, debido a la utilización del eslavo antiguo en el servicio religioso. Siglos más tarde, el lingüista Lorenzo Hervás y Panduro demostraba en su obra maestra, El catálogo de las lenguas (1783-1784), así como en el Vocabolario políglota (1787), la pertenencia del rumano a los idiomas latinos, mediante amplias listas de palabras-título que comparaban los significados de las palabras en los idiomas latinos (Sâmbrian, 2013: 116).

A partir del siglo XIV, las informaciones sobre el espacio rumano se empezaron a diversificar, llegando hasta el punto de registrar una primera mención sobre Transilvania en un portulano catalán del siglo XIV de Angelino Dulcert. Partiendo de este portulano, hacia mediados del siglo XIV se redactó el Libro del conoscimiento de todos los reinos y tierras y señoríos que son por el mundo..., que situaba geográficamente de forma errónea a Transilvania, pero que, a pesar de sus datos contribuyó a dar a conocer este territorio habitado por los rumanos. El siglo XVI marcó un punto de inflexión en las relaciones rumano-españolas y en la manera como los españoles percibían a los rumanos y a su territorio. Debido a los vínculos político-militares que se establecieron durante los reinados de Carlos V y Felipe II (como las misiones de Juan Bautista Castaldo, Bernardo de Aldana o Alfonso Carrillo en Transilvania; la correspondencia con los príncipes de Moldavia y Valaquia), las categorías de información que los españoles poseían sobre los rumanos se diversificaron y el interés por el otro aumentó.

En trabajos anteriores hemos insistido en la descripción de Transilvania, tanto en el teatro del Siglo de Oro, como en la literatura de viajes de la misma época, destacando los relatos de Bernardo de Aldana o Alfonso Carrillo. 
En esta ocasión, nos aproximaremos sin embargo a Valaquia, sobre la que nuestro viajero, Diego Galán, poseía informaciones muy interesantes acerca de las campañas antiotomanas de 1595.

El español Diego Galán (1589-1648) salió de su villa de Consuegra a muy tierna edad con el fin de «ver mundo» y cayó prisionero de los turcos en un encuentro naval. Conducido primero a Argel y luego a Constantinopla, dejó constancia de las tribulaciones sufridas en ambas ciudades en unas Memorias escritas en forma de diálogo (González Castrillo, 2011: 267).

El propósito de nuestro trabajo es, por un lado, presentar y analizar la información proporcionada por el militar español sobre Valaquia en sus Memorias y por el otro redimir en la medida de lo posible la mala fama que la obra de Galán se ganó al publicarse la edición de Manuel Serrano y Sanz, que denunciaba el estilo «desaliñado y de mal gusto», así como los errores cronológicos de los eventos históricos narrados por la obra, destacando únicamente la descripción del Partenón (Galán, 1913: XCIV). Bien es cierto que los capítulos donde Galán narra sus aventuras valacas encierran algunos errores, no tanto de datación, como sobre todo de transcripción de topónimos, aunque en este caso, puesto que ambas variantes del texto de Galán que han llegado hasta nosotros son copias manuscritas, no podemos estar plenamente seguros de si los fallos se debieron al soldado-escritor, al copista o al editor moderno. Al mismo tiempo, si fuésemos a aceptar la variante de los errores del soldadoescritor, habría que tomar en cuenta el hecho de que la redacción de las memorias de Galán es bastante posterior a los hechos narrados, lo cual hace que esta autobiografía se encuentre más próxima a la literatura oral que a la escrita; de allí los errores de transcripción de topónimos.

Sin embargo, no todo son malas palabras para este soldado del XVI. Según Gastañaga, Galán puede reclamar la preeminencia en la formación de la autobiografía novelada, ya que para el soldado-escritor, no bastaría con contar hechos sacados de la realidad, sino que esa realidad se embellece con técnicas cogidas de los grandes maestros como Góngora, las novelas picarescas, etc. (Gastañaga, 2011: 54-55). Alessandro Cassol incluye también a Galán en su lista de autobiografías de soldados, aunque destaca que su obra constituye «un enigma sin fácil solución en cuanto a su estatuto» (Cassol, 2000: 217). Claro está que el análisis de las memorias de Galán tiene que hacerse con mucha cautela, puesto que tal como indicaba Raffaele Puddu, en la literatura soldadesca, «la historia y el mito son sincrónicos» (Puddu, 1982: 10)

Para Diego Galán, tal como en su momento lo fue para Cervantes u otros soldados renacentistas, el cautiverio representó el eje central de su vida. $\mathrm{Su}$ adversa fortuna comenzó en 1598, prolongándose durante 10 años y 15 días minuciosamente contados, a los que habría que sumar un año de huída por los Balcanes, las islas del Mediterráneo oriental, Sicilia, Nápoles, Valencia y Madrid (Bunes Ibarra, 2003: 82). A su regreso a España, Galán escribió sus memorias, tituladas Cautiverio y trabajos de Diego Galán natural de Consue- 
gra y vecino de Toledo, que reúnen los eventos del periodo 1589-1600 (Barchino, 2001). Estas memorias conocieron dos variantes manuscritas. La primera versión que ha llegado hasta nosotros está atesorada por la biblioteca de El Escorial y lleva por título Relación del cautiverio y libertad y libertad de Diego Galán, natural de Consuegra y veçino de la ciudad de Toledo. La edición crítica moderna de este manuscrito pertenece a Miguel A. de Bunes y Matías Barchino y se publicó en el año 2011. Es una variante abreviada con respecto a la sucesiva y debe de entenderse como el estado de redacción de una variante anterior, probablemente original, que sirvió de base para la segunda versión, más ampliada. Esta versión ampliada, Cautiverio y trabajos de Diego Galán, natural de Consuegra y vezino de Toledo, reproducida por la edición de Matías Barchino del año 2001, se basa en el texto perteneciente a la Biblioteca pública de Toledo. La primera edición crítica de esta variante es del año 1913, cuando Manuel Serrano Sanz la publicó en la Sociedad de los Bibliófilos Españoles. Ambos manuscritos son del siglo XVIII y se diferencian, además del título, en la diferente extensión de los textos (Bunes Ibarra y Barchino, 2011: 10). Sin embargo, la crítica moderna no se ha percatado de las diferencias entre los dos manuscritos, dedicándose a reproducir el texto impreso de Serrano y Sanz.

El primero en dar a conocer el texto de Galán en Rumanía fue Alexandru Ciorănescu (1965: 77-96), que publicó fragmentos sobre Miguel el Bravo y la batalla de Călugăreni en lengua francesa, los cuales se tradujeron posteriormente al rumano, publicándose en la famosa colección de Viajeros extranjeros sobre los Países rumanos (Călători străini despre ţările române) del Instituto de Historia «Nicolae Iorga» de Bucarest (Holban, 1971: 518-537)2.

No nos dedicaremos aquí a analizar las diferencias de contenido entre los manuscritos de El Escorial y el de Toledo con respecto a la campaña antiotomana de 1595, puesto que hará el objeto de otro estudio, sino que haremos hincapié en el análisis de la información proporcionada, tomando como base el manuscrito de Toledo, debido a que la imagen presentada es más amplia.

Ambas versiones manuscritas coinciden en que a la edad de catorce años, Galán se alistó como soldado en una compañía que se dirigía camino a Orán, pero cayó prisionero mientras se encontraba en Málaga, viviendo muchas peripecias en Argel. También sirvió como paje en Constantinopla y remó en las galeras de los turcos en su campaña militar del Danubio de 1595 (Bunes Ibarra, 2003: 82).

${ }^{2}$ Alexandru Ciorănescu había conocido, tal como resulta por sus citaciones, el libro de 1913 de Serrano y Sanz al que había tomado como referencia a la hora de realizar la traducción del texto al francés, publicada en 1965. Posteriormente, la colección de Viajeros ya mencionada reprodujo en 1971 la traducción de Ciorănescu, esta vez en versión rumana, haciendo una traducción de la traducción. Es por esto que hoy día se impone una nueva traducción al rumano, directamente desde el texto español, aunque algunos fragmentos se hayan publicado ya recientemente (Sâmbrian, 2013). 
Este último momento interesa de manera especial la historiografía rumana, puesto que se llevó a cabo en territorios habitados por los rumanos, a lo largo del Danubio. Este interés se justifica de varias maneras. Para empezar, se trata de la recepción directa por parte de la mentalidad colectiva española de un evento militar muy importante: la batalla de Călugăreni del 23 de agosto de 1595, donde los turcos sufrieron una gran derrota frente a los cristianos rumanos. El historiador Alexandru Ciorănescu destacó un aspecto que le había llamado mucho la atención de este relato, insistiendo en la curiosidad del mismo. Por un lado, afirmaba Ciorănescu, se trataría de la curiosidad constante de Galán por «verlo y conocerlo todo» (1965: 77). Por otro, llama la atención la posición singular del militar español, que se sitúa físicamente del lado de los musulmanes, ya que es su prisionero, y mentalmente del lado de los cristianos, puesto que se alegra por sus victorias (Ciorănescu, 1965: 78).

A estos aspectos de interés subrayados por Ciorănescu, añadiríamos uno más: la chocante diferencia entre el relato de Galán y el del jesuita Alfonso Carrillo acerca del mismo evento, la batalla del 23 de agosto de 1595. Dos miradas muy distintas sobre la misma empresa. En la de Galán, el príncipe valaco Miguel el Bravo se llevaba la palma por la valentía demostrada en el campo de batalla. Sin embargo, la variante de Carrillo, redactada en una carta al cardenal Aquaviva y expuesta ante Felipe II, era el príncipe de Transilvania, Segismundo Báthory, el que supuestamente tenía que ser alabado por la victoria. Agente de propaganda de Báthory a lo largo de su estancia en la corte transilvana de Alba Julia, desde donde redactaba los boletines de guerra, Carrillo había preferido dejar en el olvido al príncipe Miguel por razones puramente políticas, resaltando únicamente los méritos del transilvano. Sin embargo, tal como resulta del análisis de González Cuerva, «la primera imagen de cruzado (de Segismmundo Báthoy, n.n.) que se labró de cara al público occidental fue después arruinada según se comprobaba su carácter inestable y cruel, extremo que las relaciones maquillan totalmente (...) Segismundo parece una mezcla de genio y locura, epilepsia y lunatismo, dueño de una rica sensibilidad musical, pero también con tintes sombríos, como apropiarse de los bienes de sus enemigos tras presenciar su masacre» (González Cuerva, 2006: 288). Un papel importante en la recepción ideal de Segismundo Báthory en Europa occidental fueron los grabados, que reflectaban el carácter propagandístico de legitimación del poder, mediante inscripciones como Pro Christo et Patria (Sanz Ayán, 2012: 233-234).

Más adelante, la opinión colectiva española receptó solamente la imagen ideal de Segismundo y los relatos de Carrillo, cuyas vías de propaganda eran mucho más extensas que las de un mero militar. Esto explicaría las imágenes tan sumamente positivas de Segismundo Báthory en las obras teatrales españolas de finales del siglo XVI, como El capitán prodigioso de Luis Vélez de Guevara o más adelante El príncipe prodigioso y defensor de la fe de Agustín Moreto y Juan de Matos. Todo esto a pesar de que las relaciones de sucesos de la época tienden a dar la razón a Galán. 
El relato del militar español sobre su campaña valaca encierra varios aspectos de interés, algunos de los cuales debatiremos a continuación.

Tras un atento y minucioso análisis de las memorias de Galán, observamos algunas inadvertencias en su texto, provocadas, probablemente, por la distancia en el tiempo con respecto a la fecha posterior cuando se redactó el texto. Al referirse a la rebelión de Miguel el Bravo contra los turcos de noviembre 1594, el militar español se equivoca, situándola dos años más tarde:

El príncipe Miguel Vaivoda, señor de la provincia de Valaquia, que está sujeta al Gran Turco, en la cual no tiene más de dos fortalezas, una en la ciudad de Drogujta, con guarnición de turcos y la otra en la margen del Danubio que se llama Cigáxic, sin población alguna más de sola una fuerza escueta con gruesa artillería y lucida guarnición de soldados, se rebeló en el año de mil y quinientos y noventa y seis, confiado en el favor y protección de Matías, rey húngaro, y ayuda del príncipe Transilván, que ambos confinan con su tierra (Barchino, 2001: 243)

Del fragmento citado se desprenden asimismo otras confusiones. Por ejemplo, durante el reinado de Miguel el Bravo, el rey de Hungría era Rodolfo II (1576-1608), en vez de Matías II de Habsburgo, quien, eso sí, le sucedería al trono en 1608. En el susodicho pasaje se recoge también el nombre de una de las ciudades danubianas de Valaquia, Giurgiu. La descripción es somera: ciudad situada al lado del Danubio, despoblada, con una fortaleza y una guarnición de soldados. La redacción telegráfica de estos hechos nos confirma el acercamiento progresivo del soldado español al espacio rumano. Asimismo, hay que advertir que este contacto se realiza desde el ámbito acuático y desde los remos de una galera otomana. Por tanto, es normal que la descripción sea sucinta, puesto que la actitud del soldado no era contemplativa, sino más bien activa, si tomamos en cuenta la carga física y moral a la que Galán se enfrentaba: luchar del lado de los turcos, muy en contra de su voluntad y a pesar de ser cristiano y, al mismo tiempo alegrarse de las victorias de los cristianos de los que sin embargo se veía perseguido. Prosiguiendo con la narración, Galán concluía lo siguiente sobre el príncipe Miguel:

Confiado, pues, en las palabras reales de aquellos príncipes y esperando alcanzar, con el ayuda divina y liga humana, el fin y vencimiento que deseaba, acometió con ímpetu a la fuerza que digo que tiene el Turco en la ciudad de Drogujta, a la cual rindió en poco tiempo, por ser la guarnición de los turcos poca y el poder del príncipe mucho, aunque su asistencia fue la principal causa de la victoria, porque es muy necesario para la consecución de grandes hechos la presencia y valor del príncipe y que en los mayores peligros sea el primero que aventure su vida en defensa de los reinos y vasallos para que a si imitación emprendan hazañas que admiren y espanten a las más remotas provincias y regiones (Barchino, 2001: 244).

En las afirmaciones de Galán se vislumbra la inversión de dos eventos históricos: la abyección de los turcos de Târgovişte (18 de octubre de 1595) y la batalla de Călugăreni (23 de agosto de 1595). Cabe también la posibilidad de que Diego Galán invirtiera de manera voluntaria las dos acciones de 
Miguel el Bravo (Holban, 1971: 522), con tal de resaltar y amplificar la destreza de su espada y su valentía.

Al contrario que los viajeros que llegaban a tierras lejanas y paganas y cuyo léxico se centraba en describir las diferencias entre lo conocido y lo novedoso (Cristófor Colón, Cristóbal de Acuña, etc.), Galán se hallaba en un espacio donde el otro estaba más próximo desde una perspectiva socio-cultural de lo que se podría llegar a pensar y, aunque alejado en el espacio, lo cual podía determinar la aparición de elementos descomunales, el otro tenía en común factores tan esenciales como el religioso. El príncipe cristiano en el que Galán hacía hincapié en su relato luchaba permanentemente en contra de los infieles, teniendo fe en el Dios verdadero. Las descripciones de las guarniciones reducidas de los turcos y del gran poder del príncipe valaco «por ser la guarnición de los turcos poca y el poder del príncipe mucho», bien sabiendo que los turcos se hallaban en aquel periodo en pleno apogeo de su poder, a la vez que Valaquia no dejaba de ser un principado pequeño, no han de extrañarnos, puesto que se insertan dentro de una corriente de opinión renacentista. A principios del siglo XVI, Antonio de Guevara incurría en su Reloj de príncipes en la idea de que Dios ayudaba a los príncipes creyentes, mientras que castigaba a los infieles (libro I). Hay que mencionar, aunque únicamente se quede en una mera anécdota, que en la misma época cuando Guevara escribía su libro, el príncipe valaco Neagoe Basarab (1512-1521) redactaba las Enseñanzas a su hijo, Teodosie, donde compartía las mismas ideas de Guevara (parte II, capítulo II), lo cual refuerza nuestra idea de que Galán no hizo más que reproducir en la afirmación ya alegada una mentalidad común en su época.

La figura del buen creyente, representada en este caso por Miguel el Bravo, contrasta con el retrato sangriento del sultán Mahometo III, que en la época de los eventos históricos relatados por el español se encontraba en su primer año de reinado, es decir 1595 y no 1596, tal como había apuntado el militar: «De esta rebelión tuvo tan grande enojo el sultán Mahamet, que se dijo quería salir en persona a castigar tal atrevimiento porque, por ser el primer año de su imperio, intentaba darse a conocer por su valor y hacerse temer por su crueldad».

De la decisión del sultán de ir en persona a castigar a su irreverente súbdito se hace eco no únicamente Galán, pero también las relaciones de sucesos del periodo, que apoyan las afirmaciones del soldado español. Conocemos asimismo que el 19 de junio de 1596, la imprenta sevillana de Rodrigo de Cabrera dio a conocer la «Carta de Mahometo, tercer emperador de los turcos al Serenísimo Príncipe Segismundo Batori, príncipe de Transilvania, Moldavia y Valachia» ${ }^{3}$, donde se afirmaba:

\footnotetext{
${ }^{3}$ Carta de Mahomet, Tercer emperador de los turcos, escripta al Serenisimo Segismundo Batori, Principe de Transilvania, Moldavia, Valachia. Traduzida de lengua Turquesca en
} 
mas si por el contrario, quereys perseverar en esta vuestra obstinacion de continuar guerra contra nos, os hazemos saber que dexaremos qualquier otra cosa a una parte, aunque sea grande e importante, y digno la dexaremos por poder más rigu-

Lengua Italiana en Roma, en la estampa de Gabia, en el Año de Mil y quinientos y noventa y cinco, con licencia de los Superiores. Biblioteca Nacional de Madrid, VC/224/2:

Tercer emperador de los turcos, escripta al Serenisimo Segismundo Batori, Principe de Transilvania, Moldavia, Valachia. Traduzida de lengua Turquesca en Lengua Italiana en Roma, en la estampa de Gabia, en el Año de Mil y quinientos y noventa y cinco, con licencia de los Superiores. BNM VC/224/2

Nos Mahomet Othomano, justo guerrero y vitorioso, Emperador desde el Oriente hasta el Occidente, Rey y Señor de la Suria, Egypto, Syria, Cilicia, Iudea, Panfilia, Bitinia, Armenia y otros reinos y grandísimas provincias, que damos y concedemos lugares y Señoríos y Reynos. Alexandro del mundo, Señor de señores y Rey de Reyes y de Emperadores. Mantenedor de la justicia en el mundo, y guardador de la palabra, y de la fe, Siervo cubierto con la sombra de Dios, y obediente a sus penitencias, al qual rogamos que de victoria a nuestros exercitos y que crezca su grandeza al mundo.

Con el nombre del señor y con el tenor de las presentes nuestras letras, vos excelentisimo

Sigismundo Batori, Principe de Transilvania. No tenemos ocasión de embiar mucha salud, porque os habéis revelado contra nos, mas os deseamos paz, viendo que nuestros Embaxadores que os embiamos no han podido alcançar de vos cosa ninguna de aquello que desseamos, sobre lo qual no sabemos qué imaginar, si no que os aveys fiado de dar fe a sus palabras, o más aina lo habéis hecho por echaros acuestas el despeñadero de vuestra perdición. Por la qual cosa avemos determimnado, no solo de embiaros otro Embaxador nuestro a posta, si no también escreviros la presente, y confirmarla con nuestro sello, en la cual os pondremos delante de los ojos dos cosas; la una será el afición y amor que os tenemos, acompañado con el desseo de hazeros mayor que no sois, ni jamás vuestros antepassados han sido ninguno dellos: y la otra, la destruycion que se os apareja, si no os resolveis de hazer paz con nos. Y pues, si quereis tornar a nuestra confederacion y amistad, todas las injurias y ofensas aunque sean muy grandes, o por mejor dezir, nos aveis hecho, os seran perdonadas, antes que la pena y castigo que devidamente merecen las rebeliones y solevantamientos de pueblos, y muerte de tantos nuestros Soldados, y de tantos daños de vos hechos y causados contra nos y nuestra corona, y de nuestro imperio: por lo qual, no solamente os sera perdonda, si no dada; con tal, que hagays esta paz. Y tambien os queremos galardonar, con dexaros gozar en paz vuestro Reyno de la Transilvania; y poneros en el estado de la Balachia y Moldavia: y mas hazeros Rey de la Ungria, con obligación de poner siempre nuestras armas y todo nuestro aver en vuestra defensa y de vuestros Reynos, contra quien os quisiere offender, y esto queremos hazer, porque siendo vos en semejante edad de juventud dotado de tantas y tan singulares virtudes, nos daria disgusto, que en medio de tan hermoso curso de fortuna, os hiziessemos despeñar en un profundo de miserias, como ciertamente os acontecerá, si no os resolveys de hazer una buena y perpetua paz: mas si por el contrario, quereys perseverar en esta vuestra obstinacion de continuar guerra contra nos, os hazemos saber que dexaremos qualquier otra cosa a una parte, aunque sea grande e importante, y digno la dexaremos por poder más rigurosamente castigaros, y hazeros padecer la de vida pena, por el pecado que aveys cometido; ni jamas os dexaremos en paz hasta tanto que no hayamos quemado y tomado y assolado de toda vuestra tierra, y para que me- 
rosamente castigaros, y hazeros padecer la de vida pena, por el pecado que aveys cometido; ni jamas os dexaremos en paz hasta tanto que no hayamos quemado y tomado y assolado de toda vuestra tierra, y para que mejor veays lo que teneys de hazer os traemos a la memoria, como por ventura se os acordara y aveis leydo en las antiguas memorias, como jamas no a avido Principe, ni Potencia, que resistiesse a la nuestra.

La razón por la que la carta iba dirigida a Segismundo Báthory y no al príncipe Miguel, el principal promotor de la guerra antiotomana, era el hecho de que Segismundo, tras convertirse en señor de Valaquia, era la persona con la que los demás señores más tenían que tratar a nivel de política internacional, en asuntos que atañían al vasallaje. De este hecho se aprovechó Alfonso Carrillo en su campaña de desacreditación de Miguel el Bravo, puesto que su nombre apenas figuraba en los informes, tal como hemos demostrado en trabajos anteriores.

Siguiendo la línea de las descripciones de Guevara donde los príncipes cristianos alcanzaban dimensiones sobrenaturales, advertimos el mismo discurso por parte de Galán. El Danubio se convierte en un defensor del príncipe y «sirve de defensa al Vaivoda y de freno al Turco» (Barchino, 2001: 246), las aguas van en contra de los otomanos, «la contradicción de las aguas que intentaban impedir los intentos de la jornada» (Barchino, 2001: 247), mientras que para remar en el Danubio, los barcos de los turcos tenían que «forcejear contra la corriente» (Barchino, 2001: 251). El Danubio parece, pues, más que un río, un agua bendita que gracias a sus propiedades amnióticas mantiene lejos al enemigo.

A medida que el relato avanza, Galán revela los motivos que lo habían alejado de España: «recibí gran contento por ver cada día cosas nuevas que, aun con los trabajos pasados, no se mitigó el deseo que me sacó de mi patria» (Barchino, 2001: 247), así como su esperanza y convicción de que Dios en su infinita bondad, libraría a la Cristiandad de los turcos: «Dios, por su bondad inmensa, sea servido - no mirando nuestros pecados - de acortar las fuerzas a un tan gran enemigo como en él tiene la cristiandad» (Barchino, 2001: 249).

Al igual que sus predecesores, Galán ajusta los elementos novedosos que se revelan ante sí a las realidades ya conocidas, tal como en su momento lo

jor veays lo que teneys de hazer os traemos a la memoria, como por ventura se os acordara y aveis leydo en las antiguas memorias, como jamas no a avido Principe, ni Potencia, que resistiesse a la nuestra. Acordaos tambien, que somos succesor de uno de aquellos que sojuzgo la Harieva, abatio los fuertes Safordones, enflaquecio los cuernos al Ungaro y otra vez tomó la Transilvania. Pues siendo esto la verdad, como es en efeto, y no teniendo vos resistencia contra la potencia que contra vos se os apareja poderosisima: que defensa hareys vos, quando determinaremos venir contra vos con todas nuestras fuerças y poderios. Por agora no os dezimos otra cosa, si no que lo mas presto que pudieredes procureys despachar a nuestro Embaxador, con aquella respuesta que a vos mejor parezca. Dada en Constantinopla el primero de la Luna de Octubre de Noventa y cinco. 
había hecho Colón, superponiendo las imágenes africanas ya adquiridas en sus viajes con los portugueses, encima de las descripciones del Nuevo Mundo. De la misma manera, Galán acaba comparando los paisajes montañosos de Bulgaria con los de Galicia:

Partimos de Constantinopla navegando por el canal hasta la boca del mar Negro, adonde está la torre de la linterna (...) De allí nos engolfamos para Bornu, que es una ciudad pequeña de los turcos, fundada en la provincia de la Bulgaria. Desde esta ciudad fuimos costeando hasta el cabo de San Jorge, en cuyas márgenes permanecen las ruinas de una ciudad que al parecer sería grande y populosa en su tiempo, el cual todo lo consume y acaba. Al cabo, pues, de tres días dimos vista a un lugar que está al pie de unas montañas, el cual se llama Vejtipe, que en lengua turquesca quiere decir «cinco montañas», (...) donde tomamos algún refresco, aunque poco, por ser lugar miserable y pobre como lo es casi toda aquella tierra de la Bulgaria, que es muy semejante a la parte que de España comúnmente se llama Galicia. Desde este lugar partió la armada para otro lugar cuyo nombre es Tulcha, fundado en la propia costa de la Bulgaria, en cuyo puerto se juntan y agregan todas las corrientes y brazos en que se divide y desvanece el Danubio y es capaz de muchas embarcaciones, si bien no muy seguro (Barchino, 2001: 250-253).

Durante su aventura danubiana, el soldado llega a Brăila, pero su amo le ordena remar deprisa, debido a la artillería que encerraba en sus bastiones. Finalmente, el ejército turco acampaba en Măcin:

En aquel sitio estuvimos surtos toda la noche hasta que la hermosa aurora dio aviso de que venía el hermoso desprecio de la esquiva Dafne a repartir sus luces por aquel emisferio, que partimos guiando el viaje a Cristopoli, lugar de los caravoldanes sujetos al Turco, donde se tomó refresco y de allí fuimos a una ciudad que se llama Silistra, que era población de turcos, si bien la mayor parte de ella había consumido la voracidad del fuego, según lo mostraban sus ruinas, cuya destrucción fue hecha por el vaivoda, que el invierno antes había pasado por encima del río, que a la sazón por los muchos hielos estaba sujeto y reprimido con prisiones de cristal, y le había entregado a las llamas, de quienes tan sólo se libró la fortaleza por estar escueta, sin comunicación de casas alrededor (Barchino, 2001: 257).

En este párrafo se puede vislumbrar la aparición del elemento fantástico, propio de los espacios lejanos, donde el autor menciona a Dafne, la ninfa de la que se enamoró Apolo y que pidió a Zeus que la transformase en un laurel, de modo que Apolo pudiese romper un ramo suyo y ponérselo alrededor de la frente. La aparición de Dafne al amanecer no es casual, puesto que como sabemos, Apolo era la personificación del Sol. La lejanía de su tierra empuja al militar español a escribir pasajes como éste, donde la unión entre lo mitológico y lo fantástico en una tierra remota dan pleno testimonio de la manera en que se retrata la novedad. Una novedad, tal como decíamos al principio, cercana desde el punto de vista religioso y político, lo cual determinó las comparaciones con la mitología europea común, la griega.

Al describir la batala de Călugăreni, Diego Galán se mostró impresionado por el número reducido de rumanos que plantaban cara a los turcos, imagen una vez más hiperbólica y cuya razón de ser era impresionar al lector. De esta 
forma, los turcos se habrían retirado «(...) corridos de que cuatro desnudos les hicieran tantas bajas, burlándose de ellos, pues se atrevían quinientos a tan desigual número» (Barchino, 2001: 281).

Tras la batalla de Călugăreni, los turcos consiguieron reponerse y encaminarse hacia Bucarest, intentando transformar Valaquia en paşalâc ${ }^{4}$. Es en esta seguda parte de la confrontación cuando Miguel el Bravo recibe el apoyo de Segismundo Báthory. Los ejércitos cristianos reunidos vencieron a los otomanos en Târgovişte (18 de octubre), Bucarest (22 de octubre) y Giurgiu (26 de octubre). Antes de conseguir la victoria definitiva, Valaquia conoció la violencia del saqueo turco, tal como lo demuestra el relato de Galán:

En lo que toca muebles de casa, todos andaban rodando porque cada turco escogía lo mejor y de menos embarazo, arrojando por aquellos suelos lo que no quería, conque estaban aquellos campos cubiertos y enredados con trastos. Los bajanes que andaban corriendo la tierra cada día cogían hatos de ganado, si bien la mayor parte fueron vacadas, en tanta abundancia que todos los más días no cesaba de pasar por la puente a tierra de turcos tanta cantidad de cabezas, que parecía imposible que una tierra no muy dilatada, como lo es la Valaquia, se criase tanto ganado y hubiese sustento en los campos para ellos, que verdaderamente pareció que la mitad de Europa se había despoblado de animales, lo que había bien menester. En efecto, en más de dos meses no cesaron de pasar hatos y vacadas, causando muchas quiebras en la puente y así era necesario que cada día se aderezase. Fueron pues tantas las vacadas y yeguadas que se robaron, que se vendía una vaca por cuatro reales españoles, una ternera por dos y un buen rocín por seis, y lo que es ganado menor tal como carneros, cabras, ovejas, no tenían precio porque nadie le estimaba en una blanca, por no tener venta: y así, sólo servía de que cada uno comiese lo que gustase, sacando el vientre de mal año, y lo demás lo dejaban por los campo a su albedrío, sin hacer caso de ello. Cada vez que escribo estas cosas considero que han de parecer la pena de increíbles; esto se entiende en lo que no han salido una legua de su patria, ni saben de mal ni de bien, siendo perpetuos censores de lo que no han visto, pero, con el consuelo de que no las dudarán los que han andado por el mundo viendo cada día mayores maravillas que las que escribo (Barchino, 2001: 287-288).

Las manadas infinitas de vacas gordas simbolizan en este caso, tal como ocurre en la Biblia, la presencia de la riqueza y la abundancia.

Nos hallamos, pues, ante un relato que, más allá de la información que proporciona sobre Rumanía, nos demuestra a la par los conocimientos que el español medio del siglo XVI podía poseer, debido a su educación: algún que otro elemento mitológico y, sobre todo, varias referencias religiosas, lo cual nos confirma que el español del Renacimiento era, como en su momento también lo fue el hombre medieval, antes que nada un homo religiosus.

Pero como en nuestra ponencia nos interesa sobre todo el homo viator, volvamos por un instante al relato de Galán, observando cómo sus descripciones inciden una vez más en la riqueza valaca:

\footnotetext{
${ }^{4}$ Forma administrativa que pertenecía al dar al Islam.
} 


\begin{abstract}
En medio, pues de tanta abundancia, se vio una cosa increíble al parecer y, verdaderamente, pasó al pie de la letra como lo refiero, y fue que valía más precio una libra de pan que una vaca porque, como no había quien beneficiase el trigo y semillas que estaban sembradas, a causa de estar todos los labradores, unos huidos y otros presos, y haberse aumentado tantas bocas de cautivos en el ejército y, como era fuerza darles de comer o dejarlos morir, se consumió el mantenimiento que llevaban para la jornada. En materia de pan hablo, que en lo demás todo estaba sobrado pero, como faltando pan todas las viandas sobran, no suplían tanto ganado la falta de pan, causa porque perecieron muchos turcos y cautivos porque, como se hartaban de carne de vaca y luego se echaban un golpe de agua, que lo que es vino no se hallaba un cuartillo por cien ducados, les sobrevinieron mil enfermedades de cámaras y calenturas, con que en breve tiempo faltó mucha gente del campo (Barchino, 2001: 288-289).
\end{abstract}

El relato de Galán sobre el Danubio y sus ciudades mantiene, a nuestro parecer, algo del imaginario colectivo español del conquistador o del descubridor. Una vez hallado frente a lo nuevo, el soldado español se relaciona a él, ya sea mediante descripciones someras y objetivas, ya sea mediante el miraje de lo fantástico. Entre el Danubio visto por Galán y el Amazonas de Acuña, por ejemplo, hay un acercamiento muy interesante de cara a la percepción del agua. El mismo Danubio que para los rumanos representaba una fuente de protección y de abundancia, comportaba características nocivas para los turcos, que, al beber de sus aguas, caían enfermos y morían. El universo acuático rumano aparece como un espacio abierto, pero cerrado al mismo tiempo a aquellos que lo desconocen; un espacio profundo y místico, que reúne a la vez elementos cristianos y paleocristianos, lo cual puede ser un indicio de las confusiones que el espacio «lejano-amigo» provocaba en las mentes de aquellos que lo llegaban a pisar.

Claro está que el relato de Galán, al igual que las autobiografías de soldados en general, hay que analizarlo con cautela, puesto que bien es sabido que los militares exageraban la dimensión de sus hazañas, destacando sobre todo su propia figura y sus grandes méritos. La técnica del miles gloriosus se aplica para gran parte de este tipo de relatos, aunque no por ello hay que menospreciar la información evenimencial proporcionada. En el caso del relato sobre Valaquia, lo que nos interesa de manera especial es la forma como Galán se aproxima a este espacio, cómo lo enfoca y lo describe, cómo lo percibe o cree percibirlo. Porque al fin y al cabo, en una sociedad renacentista que tan poca idea tenía del espacio rumano, por lo menos a nivel macro social, cualquier información nos puede valer para comprender cómo se forjará la futura imagen rumana/valaca en la mentalidad colectiva española. Pionero entre sus compatriotas por la extensión de su narración sobre Valquia, al relato de Diego Galán le corresponde un papel muy importante en el descubrimiento paulatino y en la integración incipiente de la cultura rumana al imaginario español. 


\section{BIBLIOGRAFÍA CITADA}

Barchino, Matías (2001). Edición crítica de Cautiverios y trabajos de Diego Galán. Cuenca: Ediciones de la Universidad de Castilla-La Mancha.

Bunes Ibarra, Miguel Ángel de (2003). «La vida en dos redacciones de un cautivo de Consuegra: Diego Galán Escobar», Añil [en línea]. 25, pp. 81-82, disponible en http://biblioteca2.uclm.es/ biblioteca/ceclm/ARTREVISTAS/a\%C3\%B1il/a\%C3\%B1il_25/MAbunes_cautivo Consuegra.pdf [Ref. de 21 octubre 2015].

Bunes Ibarra, Miguel Ángel de y Matías Barchino (2011). Relación del cautiverio y libertad de Diego Galán. Sevilla: Espuela de Plata.

Cassol, Alessandro (2000). Vita e scrittura. Autobiografie di soldati spagnoli del Siglo de Oro. Milano: LED.

Ciorãnescu, Alexandru (1965). «Un témoin espagnol de la campagne roumaine de 1595», Revue des études roumaines. IX-X, pp. 77-96.

Galán, Diego (1913). Cautiverio y trabajos de Diego Galán natural de Consuegra y vecino de Toledo. Introducción de Manuel Serrano y Sanz. Madrid: Sociedad de Bibliófilos Españoles.

Gastañaga, José Luis (2011). Caballero noble desbaratado. Autobiografía e invención en el siglo XVI. Ashland: Purdue University Press.

González Castrillo, Ricardo (2011). «Cautivos españoles evadidos de Constantinopla en el siglo XVI», Anaquel de Estudios Árabes. 22, pp. 265-278.

González Cuerva, Rubén (2006). «El prodigioso príncipe transilvano: la larga guerra contra los turcos (1593-1606) a través de las relaciones de sucesos», Studia Historica. Historia Moderna. 28, pp. 277-299.

Holban, Maria (1971). Călători străini despre ţările române, vol. III. Bucureşti: Editura Ştiinţifică.

Puddu, Raffaele (1982). Il soldato gentiluomo. Autoritratto di una società guerriera: la Spagna del Cinquecento. Bologna: Il Mulino.

Sâmbrian, Oana Andreia (2012). «Historia e historias. La visión de Transilvania en el teatro del Siglo de Oro», en Oana Andreia Sâmbrian, Mariela Insúa y Antonie Mihail (ed.), La voz de Clío: imágenes del poder en la comedia histórica del Siglo de Oro. Craiova: Editura Universitaria, pp. 25-47.

Sâmbrian, Oana Andreia (2013). Convergenţe româno-spaniole de la Renaştere la Modernism. Bucureşti: Editura Academiei Române.

Sanz Ayán, Carmen (2012). «Elementos para la construcción de la imagen ideal de un príncipe cristiano de frontera: Segismundo Báthory, príncipe de Transilvania», Hispania felix. 3, pp. 213-249.

Fecha de recepción: 13 de febrero de 2014.

Fecha de aceptación: 16 de junio de 2014. 